\title{
ANALISIS ANTRIAN DALAM PENDAFTARAN PENGOBATAN PASIEN MENGGUNAKAN METODE FISHBONE (STUDI KASUS : RSUD MOEWARDI SOLO)
}

\author{
Anita Megayanti ${ }^{1}$, Roy Amrullah ${ }^{2}$ \\ 1,2 Jurusan Sistem Informasi Fakultas Teknologi Informasi Universitas Serang Raya \\ Jln. Raya Cilegon Serang - Drangong Kota Serang \\ ${ }^{1}$ Anita.megayanti @gmail.com \\ ${ }^{2}$ Roy.amrullah@gmail.com
}

\begin{abstract}
Abstrak - Persaingan dalam pelayanan didalam rumah sakit saat ini semakin ketat. Hal ini berawal dari pendaftaran pengobatan pasien yang sering kali mengalami antrian yang panjang sehingga menuntut agar pelayanan lebih berkualitas maka mengurangi antrian tersebut. Penelitian ini bertujuan agar rumah sakit memberikan pelayanan yang baik terhadap pasiennya sehingga yang sakit tidak menambah sakitnya dengan lama mengantri. Setelah dilakukan identifikasi berbagai sebab potensial dari satu masalah menggunakan metode fishbone diagaram maka dihasilkan untuk membuat aplikasi online pendaftaran berbasis SMS Gateway atau aplikasi mobile.
\end{abstract}

Kata kunci-Pendaftaran Online, Metode Fishbone, Sms Gateway.

Abstract - Competition in service within the hospital is increasingly tight. This begins with the registration of patients who often experience long queues that demand that the service is more qualified then reduce the queue. This study aims to provide hospitals to provide good services to patients so that the sick did not increase the pain with long queue. After identifying the potential causes of one problem using the fishbone method diagaram then generated to create an online application registration based SMS Gateway or mobile application.

Keywords - Online Registration, Fishbone Method, Sms Gateway.

\section{PENDAhUluan}

Pelayanan-pelayanan medis saat ini bergerak maju ke depan dengan sangat aktif dan dinamis. Pergerakan ini didukung

dengan adanya tantangan yang semakin luas dan kompleks pada perkembangan teknologi informasi yang semakin maju. Situasi ini mendorong pihak pelayanan masyarakat harus cepat dan tanggap dalam menjalankan fungsi dan tanggung jawabnya, terutama dalam memperoleh kepercayaan masyarakat serta memenuhi pelayanan masyarakat yang aman, nyaman dan berkualitas.

RSUD Moewardi adalah salah satu rumah sakit daerah yang berada di solo, sebagai instansi pemerinatah yang bergerak dibidang pelayanan kesehatan, maka harus memberikan pelayanan terbaik kepada masyaakat terutama dalam menangani pasien. Untuk menghadapi persaingan antar instansi medis yang semakin ketat, masing-masing Rumah sakit harus mengembangkan konsep "pelayanan terbaik bagi pasiennya", hal ini bertujuan agar pasien merasa nyaman, aman dalam melakukan pengobatan terutama antrian pendaftaran dalam pengobatan.

Pasien akan merasa puas bilamana dalam proses pendaftaran tidak mengalami antrian yang panjang karena aktivitas tersebut memutuhkan energy yang besar untuk selalu sabar menanti giliran , alhasil pasien bisa jadi semakin parah sakitnya dikarenakan menunggu antrain pendaftaran yang cukup membosankan dan melelahkan.

Setelah peneliti melakukan analisa masalah antrian pendaftaran dalam pengobatan pasien dengan menggunakan metode fishbone maka masalah akan dipecahkan menjadi beberapa kategori yang berkaitan mencakup manusia, metode, material dan lingkungan.

\section{Metodologi Penelitian}

Studi literatur dilakukan dengan tujuan untuk menunjang penelitian yang akan dilakukan, dimana studi ini berisikan pengetahuan secara teoritis yang peran dalam pengumpulan informasi secara lengkap dalam pemecahan masalah yang akan diteliti.

Teori-teori tersebut berasal dari buku-buku referensi, jurnal, skripsi, internet dan sumber-sumber lainnya yang berhubungan dengan Analisa masalah menggunakan metode fishbone.

Pengertian Metode Penelitian menurut Sugiyono (2014:2) adalah: "Metode penelitian diartikan sebagai cara ilmiah untuk mendapatkan data dengan tujuan dan kegunaan tertentu".

Metode penelitian yang penulis gunakan dalam penelitian ini adalah penelitian deskriptif dengan pendekatan 
survey. Metode penelitian survey digunakan untuk mendapatkan data dari tempat tertentu yang alamiah (bukan buatan), tetapi peneliti melakukan perlakuan dalam pengumpulan data, misalnya dengan mengedarkan kuesioner, wawancara terstruktur, dan sebagainya.

Observasi dilakukan untuk melihat secara langsung keadaan pendaftaran pengobatan pasien di RSUD moewardi solo, sehingga didapat bahan untuk rumusan masalah dan penetapan tujuan penelitian. Pada tahap ini penulis langsung mewawancara beberapa pasien yang dating ke RSUD Moewardi solo untuk berobat.

Penelitian pada dasarnya untuk menunjukan kebenaran dan pemecahan masalah atas apa yang diteliti untuk mencapai tujuan tersebut, dilakukan suatu metode yang tepat dan relevan untuk tujuan yang diteliti.

Penulis juga menggunakan metode analisis Fishbone Diagram dalam memecahkan masalah, sebagai berikut :

a. Menentukan tema dan pokok permasalahan

b. Menganalisis sebab - akibat berdasarkan data dengan menggunakan fishbone analysis.

1) Menggambarkan garis horizontal dengan tanda panah pada ujung sebelah kanan dan suatu kotak di depannya yang berisi masalah yang diteliti

2) Menuliskan penyebab utama dalam kotak yang dihubungkan ke arah garis panah utama

3) Menuliskan penyebab kecil disekitar penyebab utama dan menghubungkannya dengan penyebab utama

c. Menentukan sebab-sebab potensial dari permasalahan dan menentukan penyebab yang paling dominan dari permasalahan yang terjadi

d. Menentukan rencana penanggulangan untuk memecahkan permasalahan yang ada.

\section{HASIL DAN PEMBAHASAN}

\subsection{Tinjauan Pustaka}

\subsubsection{Pendaftaran Pasien}

Proses pendaftaran pasien adalah awal dari keseluruhan proses rekaman medis atau pelayanan pertama kali yang diterima oleh seorang pasien saat tiba di rumah sakir, dalam proses pendaftaran inilah pasien mendapatkan kesan baik atupun tidak baik dari suatu pelayanan dari rumah sakit. Oleh karena itu pada system pendaftaran ini petugas harus bersikap ramah, sopan, tertin dan bertanggung jawab agar pasien merasa diperhatikan dan dilayani dengan baik.

Dalam system oendaftaran biasanya pasien diterima sebagai pasien rawat jalan, rawat inap, dan rawat UGD. Pasien dikatakan menjalani pengobatan rawat jalan apabila kondisi pasien tidak begitu buruk dan keadaannya masih normal-normal saja. Pasien menjalani pengobatan rawat inap bila kondisi pasien memerlukan perawatan yang intensif, sedangkan pasien yang menjalani perawatan UGD apabila kondisi pasien dalam keadaan parah, tidak sadarkan diri dengan kata lain sudah benar-benar buruk.

Sistem pendaftaran pasien di RSUD moewardi dibedakan menjadi 2 (dua) bagian yaitu : a. Pasien Baru

Pendaftaran pasien baru akan dilaksanakan dengan mengisi formulir pendaftaran terlebih dahulu untuk mendapatkan data social pasien yang akan dimasukkan dalam computer. Setiap pasien baru akan memperoleh nomor pasien, kemudian pasien akan diberikan kartu berobat yang harus dibawa setiap kali pasien tersebut dating kembali untuk berobat ke RSUD Moewardi, solo.

b. Pasien Lama

Pendaftaran pasien lama dilakukan dengan mencari berkas rekam medis pasien dengan menginput nomor pasien sesuai dengan Nomor Rekam Medis yang tercantum dalam kartu berobat, setelah itu membuat tracer, mencetak nomor urut poliklinik, mencetak kwitansi oemabyaran, dan mengarajkan pasien sesuai dengan tuuan poliklinik.

\subsubsection{Fishbone Diagram}

Fishbone diagram adalah salah satu metode / tool didalam meningkatkan kualitas. Sering juga diagram ini disebut dengan diagram sebab akibat atau cause effect diagram. Penemunya adlaah seoranga ilmuwan jepang pada tahun 60.an bernama Dr. Kaoru Ishikawa, ilmuwan kelahiran 1915 ditokyo. Metode ini awalnya lebih banyak digunakan untuk manajemen kualitas, yang mengunakan data verbal atau data kualitatif.

Fishbne diagram telah menciptaan ide cermelang yang dapat membantu dan memampukan setiap orang atau organisasi/perusahaan dalam menyelesaikan masalah dengan tuntas sampai ke akarnya.

Dengan adanya Fishbone diagram

Ini memberikan banyak sekali keuntungan bagi dunia bisnis. Selain memecahkan masalah kualitas juga dipergunakan untuk kebutuhan-kebutuhan sebaga berikut :

a. Membantu mengidentifikasi akar penyebab dari suatu masalah

b. Membantu membangkitkan ide-ide untuk solusi suatu masalah

c. Membantu dalam penyelidikan atau pencarian fakta lebih lanjut

d. Mengidentifikasi tindakan untuk menciptakan hasil yang diinginkan

e. Membahas issue secara lengkap dan baru

f. Menghasilkan pemikiran baru

\subsubsection{RSUD Moewardi Solo}

RSUD moewardi Solo beralamat J1. Kolonel Sutarti 132 Surakarta dengan email rsmoewardi@ jatengprov,go.id.

RSUD Dr. Moewardi adalah rumah sakit yang memberikan pelayanan kesehatan dengan mutu yang setinggi-tingginya dan melaksanakan fungsi pendidikan kesehatan di rumah sakit dengan sebaik-baiknya yang diabadikan bagi kepentingan peningkatan derajat kesehatan masyarakat. Yang mempunyai visi menjadi rumah sakit terkemuka diindonesia, eksis dan berkembang serta mampu menghadapi perubahan yang semakin berat dan kompleks, melalui penerapan standarstandar nasional maupun internasional (pelayanan, pendidikan dan penlitian). 
Misi dari RSUD Dr. MOewardi tersebut adalah menyediakan pelayanan kesehatan berbasis pada keunggulan sumber daya manusia, kecanggihan dan kecukupan alat serta profesionalisme manajemen pelayanan dan menyediakan wahana pendidikan dan penelitian kesehatan yang unggul berbasis pada perkembangan ilmu pengetahuan dan teknologi kesehatan yang bersinergi dengan mutu pelayanan.

\subsection{Analisis Permasalahan}

Analisis permasalahan dilakukan dengan menggunakan kerangka Fishbone atau tulang ikan. Adapun permasalahan yang muncul diidentifikasi dengan menggunakan kerangka Fishbone yaitu pada gambar 1 sebagai berikut :

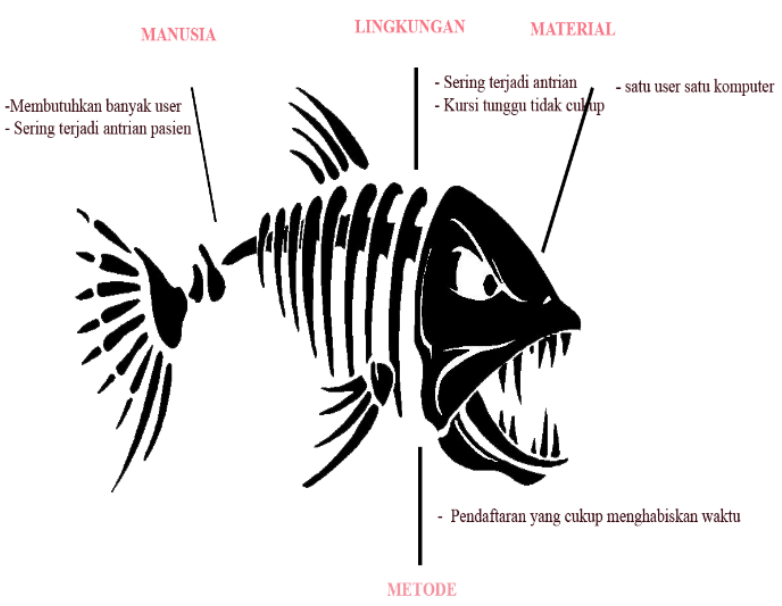

Gambar 1. Fishbone Diagram

Adapun hasil analisis yang dilakukan melalui Fishbone diagram diatas dapat dilihat pada tabel 1 sebagai berikut :

Tabel 1. Analisis Fishbone Diagram

\begin{tabular}{|l|l|l|}
\hline No & \multicolumn{1}{|c|}{ Cause } & \multicolumn{1}{|c|}{ Keterangan } \\
\hline 1. & Manusia & \multicolumn{2}{|c|}{} \\
\hline & Membutuhkan Banyak User & Potential Cause \\
\hline & Sering terjadi antrian pasien & Potential Cause \\
\hline 2. & Lingkungan & \\
\hline & Sering terjadi antrian & Potential Cause \\
\hline & Kursi tunggu tidak cukup & Most Posible Cause \\
\hline 3. & Material & \\
\hline & Satu user satu komputer & Most Posible Cause \\
\hline 4. & Metode & \\
\hline & Pendaftaran yang Pendaftaran yang cukup & \\
& menghabiskan waktu & Potential Cause \\
\hline
\end{tabular}

Faktor - factor yang menyebabkan hal tersebut adalah :
1. Pasien merasa tidak ada kenyamanan dalam proses pendaftaran dikarenakan antrian yang cukup panjang dengan cara berdiri dikarenakan fasilitas tempat duduk sangat terbatas, terlebih dengan adanya pasien BPJS

2. Bag. Pendaftaran membutuhkan tenaga kerja yang banyak guna melayani pasien yang hendak mendaftar.

\subsection{Analisis Penyebab Masalah}

Dari analisis Fishbone Diagram sebelumnya didapatkan bahwa sebab yang paling mungkin yang menyebabkan antrian dalam pendaftaran pengobatan sebagai :

1. Faktor : Manusia

Masalah : Membutuhkan banyak user

Penyebab : Di butuhkan banyak user untuk mengurangi antrian

Akibat : Tidak efesien

2. Faktor : Lingkungan

Masalah : Kursi tunggu tidak cukup

Penyebab : Fasilitas kursi yang di sediakan sedikit sedangkan pasien yang mengantri banyak.

Akibat : Pasien harus mengantri sambil berdiri

3. Faktor : Material

Masalah : Satu user satu computer

Penyebab : Pengisian data harus dilakukan melalui form pada aplikasi

Akibat : Mengeluarkan dana lebih untuk pengadaan computer

4. Faktor : Metode

Masalah : Pendaftaran yang cukup menghabiskan

waktu

Penyebab : Pengisian form yang dilakukan pada loket pendaftaran menghabiskan cukup banyak waktu

Akibat : Terjadi antrian

Keterangan diatas berdasarkan dari survey dan kusioner beberapa pasien sehingga secara garis besar bahwa analisa Penyebab masalah, yaitu :

1. Manusia”Dibutuhkan Banyak User Untuk Mengurangi Antrian"

Dalam melakukan pelayanan yang terbaik rumah sakit membuka loket lebih banyak untuk pendaftaran, ini menjadi masalah untuk rumah sakit berarti dengan adanya penamhan loket baru berartipula menambah tenaga kerja/operator untuk mengoperasikan aplikasi.

2. Lingkungan "Fasilitas Kursi yang disediakan sedikit sedangkan pasien yang mengantri banyak"

Keberadaan pasien dalam mengantri bisa duduk ditempat yang telah disediakan tetapi jika pasien yang datang banyak melebihi koridor loket pendaftaran maka banyak pasien yang terpaksa harus berdiri sehingga bila pasien yang semula hanya sakit batuk pilek bisa menambah sakitnya dengan kestresan dalam menunggu antrian.

3. Material "Pengisian data harus dilakukan melalui form pada aplikasi"

Untuk menghindari antrian yang cukup banyak maka rumah sakit moewardi harus menyiapkan loket 
pendaftaran lebih banyak lagi guna melakukan pelayanan kepada pasien yang mendaftar.

4. Metode "Pengisian form yang dilakukan pada loket pendaftaran menghabiskan cukup banyak waktu"

Pasien berbondong-bondong datang ke rumah sakit untuk berobat dimana prosedurnya terlebih dahulu melakukan pendaftaran pada loket pendaftaran yang masih konvensional, harus mantri terlebih dahulu kemudian bak. Pendaftaran melakukan entry daftar ke aplikasi yang mmebutuhkan waktu cukup banyak, untuk itu maka dibutuhkannya pendaftaran yang bisa diakses oleh pasien itu sendiri (self Service).

\subsection{Rencana Dan Target}

Hasil penyebab diatas penulis merencanakan dan membuat target agar mengurangi antrian dalam pendaftaran pengobatan di RSUD Moewardi dengan mengunakan metode 5W1H, sebaga berikut :

1. Penyebab : Membutuhkan banyak user

What : Membuat Sistem Client Server sehingga mengurangi kebutuhan tenaga user / admin

Why : Untuk meminimalisir sumber daya manusia

Who : Anita Megayanti

Where : RSUD Moewardi

When : 5 Maret 2015

How : Dengan di buatnya system ini di harapkan dapat mengurangi jumlah user

2. Penyebab : Fasilitas kursi yang di sediakan sedikit sedangkan pasien yang mengantri banyak.

What : Membuat system yang dapat di akses dimana saja sehingga tidak perlu menunggu saat mendaftar

Why : Agar mengurangi jumlah antrian

Who : Roy Amrullah Ritonga

Where : RSUD Moewardi

When : 1 Maret 2015

How : Dengan di buatnya system ini di harapkan mampu mengurangi jumlah antrian.

3. Penyebab : Pengisian data harus dilakukan melalui form pada aplikasi.

What : Membuat system yang dapat di akses langsung oleh pasien.

Why : Agar dapat mengurangi kebutuhan computer sebagai sarana yang di gunakan untuk menangani pendaftaran pasien

Who : Roy Amrullah Ritonga

Where : RSUD Moewardi

When : 1 Februari 2015

How : Dengan di buatnya system ini di harapkan bisa menghemat anggaran

4. Penyebab : Pengisian form yang dilakukan pada loket pendaftaran menghabiskan cukup banyak waktu

What : Membuat system pendaftaran dan booking yang bisa di lakukan di mana saja menggunakan mobile phone.

Why : Agar tidak terjadi antrian
Who

: Roy Amrullah Ritonga dan Anita Megayanti

Where : RSUD Moewardi

When : 1 Januari 2015

How : Dengan adanya sub system ini di harapkan dapat menghilangkan masalah antrian saat mendaftar.

Berdasarkan rencana diatas maka team peneliti sepakat untuk mencapai target yang diinginkan :

1. Pasien melakukan pendaftaran dengan menggunakan SMS Gateway guna mengurangi antrian pada loket pendaftaran.

2. Pasien juga bisa mengakses http://rsmoewardi.com/rsdm-booking/ jika ingin melakukan pendaftaran dimanapun berada.

3.5 Pelaksanaan Perbaikan

Dalam melaksanakan perbaikan, team peneliti melaksanakan bulan februari untuk menguji kegiatan yang sudah direncanakan.

1. Penyebab : Membutuhkan banyak user

Penanggulangan : Membuat Aplikasi SMS Gateway

PIC : Anita Megayanti

When : 21-28 Januari 2015

Deskripsi : Pasien dapat melakukan registrasi melalui SMS.

2. Penyebab : Fasilitas kursi yang di sediakan sedikit sedangkan pasien yang mengantri banyak.

Penanggulangan : Membuat systen yang dapat diakses dimana saja sehingga tidak perlu menunggu saat mendaftar

PIC : Roy Amrullah Ritonga

When :28 Januari 2015

Deskripsi : Membuat notifikasi pendaftaran sebagai bukti telah registrasi lewat mobile, sehingga pasien hanya memberikan kepada burse station tanpa harus antri daftar.

3. Penyebab : Pengisian data harus dilakukan melalui form pada aplikasi.

Penanggulangan : Membuat sysetm yang dapat diakses langsung oleh pasien

PIC : Roy Amrullah Ritonga

When : 25-27 Januari 2015

Deskripsi : Menyiapkan modem untuk palikasi mobile regitration

4. Penyebab : Pengisian form yang dilakukan pada loket pendaftaran menghabiskan cukup banyak waktu

Penanggulangan : Membuat system endaftaran dan booking bisa dilakukan dimana saja mengunakan mobile phone.

PIC : Roy Amrullah Ritonga dan Anita Megayanti

When : $21-24$ Januari 2015

Deskripsi : Mendesign aplikasi registrasi pasien secara mobile. 
3.6 Hasil Perbaikan

Dari hasil rencana dan perbaikan maka tes menyimpulkan untuk hasil perbaikan sebagai berikut :

1. Pasien antri diloket pendaftaran \pm 2 jam disebabkan karena pengisian for yang dilakukan pada loket pendaftaran menghabiskan cukup banyak waktu.

2. $90 \%$ masih menggunakan tenaga operator untuk menginput data pasien ke aplikasi disebabkan Pengisian data harus dilakukan melalui form pada aplikasi dan Membutuhkan banyak user

3. $85 \%$ pasien merasa tidak nyaman menunggu daftar panggil registrasi disebabkan Fasilitas kursi yang di sediakan sedikit sedangkan pasien yang mengantri banyak.

Perbandingan sebelum dan sesudah perbaikan terhadap QCDSME :
1. Aspek Mutu
: Quality
Kriteria Evaluasi : Kinerja Staff
Sebelum
a. Teller pendaftaran harus input data pendaftaran ke aplikasi d

b. Pasien masih harus antri panjang diloket pendaftaran Sesudah

a. Meringankan pekerjaan teller pendaftaran karena sudah ada system otomatis
b. Pasien tidak perlu antri panjang untuk pendaftaran cukup akses web ke http://rsmoewardi.com/rsdm- booking/ atau SMS

2. Aspek : Cost

Kriteria Evaluasi : Kecepatan Informasi

Sebelum :
a. Menyediakan loket pendaftaran lebih banyak sehingga adanya penambahan tenaga kerja untuk operator pendaftaran

b. Dengan adanya loket pendaftaran yang banyak maka dibutuhkan PC lebih banyak lagi sesuai dengan jumlah loket

Sesudah
a. Menurunkan biaya tenaga kerja di bagian pendaftaran karena pasien bisa melakukan pendaftaran otomatis.
b. Pengadaan PC lebih sedikit karena mengurangi pelayanan kepada pasien di bag.pendaftaran

3. Aspek Mutu : Delivery

Kriteria Evaluasi : Biaya

Sebelum : Pasien harus mengisi formulir pendaftaran sehingga harus menyediakan formulir pendaftaran yang sudah dicetak oleh pihak rumah sakit

Sesudah : Lebih ekonomis, karena pencetakan formulir pendaftaran relatif sedikit dibandingkan sebelum adanya.

4. Aspek : Safety

Kriteria Evaluasi : Kontrol terhadap data

Sebelum : Dilakukan input data oleh bak.loket pendaftaraan sehingga rawan human eror karena pasien yang terlalu banyak/panjang
Sesudah e-ISSN: 2581-2181

: Mudah melakukan pendaftaran pasien, cukup melakukan sms tanpa adanya antrian panjang.

5. Aspek : Moral

Kriteria Evaluasi : Kecepatan pelayanan

Sebelum

a. Waktu dan biaya yang dikeluarkan lebih banyak

b. Terbatasnya jarak dan waktu

Sesudah

a. Lebih efektif, efisien dan hemat

b. Tidak terbatas jarak dan waktu

6. Aspek : Environment

Kriteria Evaluasi : Kontrol terhadap data

Sebelum

a. Sering terjadi human eror dikarenakan satu orang/teler input beberapa pasien

b. Kebiasaan pasien yang tidak mau melakukan pendaftaran via web

Sesudah

a. Mengurangi antrian pasien dalam melakukan pendaftaran

b. Membiasakan pasien menggunakan fasilitas tehnologi masa kini.

Standarisasi untuk Format SMS Gateway :

a) Untuk Pasien BPJS

Ketik : *Nomor pasien*kode spesialis*kode dokter* tgl (format : mm/dd/yyyy) *jadwal(Pagi/Sore)*kode penjamin*nomor BPJS*nomor rujukan*

Example :

*00000661*9190*D375*27/05/2015*P*0038*00015 39258759*

Hasil notifikasi :

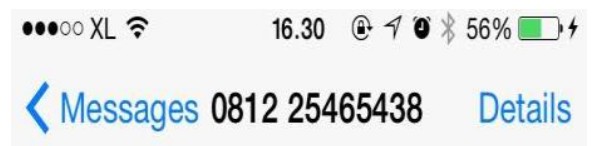

Text Message

Hari ini 13.44

${ }^{*} 00000661^{*} 9190^{\star} \mathrm{D} 375^{\star} 6$

$18 / 2015^{*} P^{*} 0038^{*} \underline{000153}$

$\underline{9258759}$

Pendaftaran Booking
atas nama RATIH
WULAN DARI NN telah
berhasil. kode Booking
anda adalah
150618 B007.
Terimakasih

Gambar 2. Display Notifikasi SMS Gateway 
b) Untuk Pasien Non BPJS ( asuransi , umum, dll )

Ketik : *Nomor pasien*kode spesialis*kode dokter* $\operatorname{tgl}$ (format : mm/dd/yyyy) *jadwal(Pagi/Sore)*kode penjamin*

Example :

*00000661*9190*D375*27/05/2015*P*0038*

\section{KESIMPULAN}

Data yang diperoleh :

Total jumlah pasien seluruh RS. Moewardi : 4302 pasien

Total jumlah pasien perhati rata-rata mencapai : 1200 pasien Total jumlah pasien mendaftar Online per hari : 214 pasien Jadi rata-rata antrian per hari diturunkan sebesar :

$=\underline{214} * 100$

1200

$=17,88 \%$

Berdasarkan hasil perbaikan dan telah sosialisasi dari tol 15 - 20 Feb 2015 diperoleh hasil menurunkan antrian sebesar $17,88 \%$ karena melakukan sms gateway.

\section{REFERENSI}

[1] Arief Suhardiono, Aris Nur Bawani, "Sistem Monitoring Traffic Packet Internet Melalui WAP Berbasis Simple Network Management Protocol (SNMP)", Politeknik Elektronika Negeri Surabaya, Surabaya, 2003

[2] Firman Arifin, Nanang Syahroni, Adi Prayitno, "Sistem Monitoring Traffic Packet Internet Melalui SMS Berbasis SNMP”, Prosiding IES, PENS-ITS. 2004.

[3] Iskandar, P. 2003. Teknik Pemanfaatan Analisis SWOT Tanpa Skala Industri. Jurnal Ekonomi \& Bisnis. No 2 Jilid 8.

[4] Kadir, abdul. 2005 . Pemrograman Database dengan Delphi 7 Menggunakan Access ADO. Yogyakarta : Penerbit Andi.

[5] Khang, Bustam. "Trik Pemrograman Aplikasi Berbasis SMS”, Elex Media Komputindo, Jakarta, 2002.

[6] Kurniawan, Agus. 2002. Pemrograman jaringan internet dengan visual C++. Jakarta : PT. Elex Media Komputindo.

[7] MADCOS . 2007 . Pemprograman Borland Delphi 7 Seri Panduan Pemprograman. Yogyakartta: Penerbit Andi

[8] Rosa, A.S dan M. Shalahuddin. M 2013, Rekayasa Perangkat Lunak Terstruktur dan Berorientasi Objek, Informatika, Bandung.

[9] Widiadhi, Tosef. Teddy Marcus Zakaria. 2006. Aplikasi SMS untuk Berbagai Keperluan. Bandung : Penerbit Informatika. 